\title{
Hulless barley: A new era of research for food purposes
}

\author{
Shaveta $^{1}$, Harinderjeet Kaur ${ }^{* 2}$ and Simarjit Kaur ${ }^{2}$ \\ ${ }^{1}$ Department of Biochemistry, Punjab Agricultural University, Ludhiana 141004, Punjab, India \\ ${ }^{2}$ Department of Plant Breeding and Genetics, Punjab Agricultural University, Ludhiana 141004, Punjab, India
}

\section{Article history}

Received: 03 Oct., 2018

Revised : 28 Aug., 2019

Accepted: 31 Aug., 2019

\section{Citation}

Shaveta, H Kaur and S Kaur 2019. Hulless barley: A new era of research for food purposes. Journal of Cereal Research 11(2): 114-124 doi.org/10.25174/2249-4065/2019/83719

*Corresponding author

Email: harinderjeet_pau@pau.edu

(C) Society for Advancement of Wheat and Barley Research

\begin{abstract}
Barley (Hordeum vulgare $\mathbf{L}_{\text {. }}$ ) is included in the family of grasses and is the fourth highly significant crop after maize, wheat and rice. Barley is considered as an important food ingredient because of the presence of vital biochemical constituents viz. $\beta$-glucan, starch, amylose, protein etc. Barley is usually classified as hulless or hulled types (absence or presence of hull adhering to grain). Hulless barley needs negligible processing and preserves maximum of the endosperm and germ, which is once in a while lost during the time spent for dehulling. As a result, it is highly suitable for human utilization, as the entire grain can be specifically utilized to form a meal or processed into flour. Interest in the use of hulless barley as a food grain has expanded primarily due to its stated health benefits.The regular intake of hulless barley contributes to maintenance of normal blood cholesterol level, beneficial in preventing certain types of cancer like colon cancer and also provides better glucose and insulin responses. Hulless barley has high $\beta$-glucan content which helps in lowering of glycemic index and also causes the stimulation of bowel health. For this reason food industry is anxious about expanding the utilization of these cereals as nourishment fixings and henceforth more research is merited here.
\end{abstract}

Keywords: Hulless barley, health benefits, $\beta$-glucan, Amylose

\section{Introduction}

Barley (Hordeum vulgare L.) stands out amongst most significant cereal grain crop and positions fourth after maize (Zea mays), wheat (Triticum spp.) and rice (Oryza sativa) (FAOSTAT, 2018). It is diploid, self-pollinating crop having 14 chromosomes. The top most barley producing nations are Russia, Germany, France and Ukraine. Barley occupies 49.60 million ha area with 144.26 million tons production worldwide whereas in India it occupies 0.68 million ha area with 1.79 million tons production (Anonymous, 2017). It is a Rabi season crop and in India, major barley producing states are Rajasthan, Punjab, Uttar Pradesh, Madhya Pradesh, Bihar and Haryana. Barley is highly adaptable cereal grain crop as it has ability to grow at higher latitudes and altitudes when contrasted with some other cereal grain species. Takahashi (1955) indicated by an examination that hulless barley is extensively dispersed, however its frequency significantly varied among locales. The dissemination of hulless barley is skewed in the direction of East Asia as 95\% of it grows in the plateaus of Japan, Korea, Nepal, Tibet of China and Bhutan. Hulless barley is comparatively grown in Ethiopia at low recurrence (Assefa and Labuschagne, 2004) and has been not really grown in Australia along with the western world. Hulless barley hereditary assets in China are richest throughout the world and it possesses $77 \%$ of the world's aggregate hulless barley hereditary assets (Lu, 1995). Barley cultivars vary anatomically in the spike structure i.e., 2 and 6 rowed cultivars or in the growth pattern like between winter and spring-type barley genotypes. Hulled barley has the caryopsis covered with the hull. Hulless barley is rich in nutritional constituents like $\beta$-glucan, limiting amino acids, starch and total dietary fiber as compared to its hulled types (Boros et al., 1996). Hulless barley has higher levels of starch and lesser fiber concentration therefore have greater digestible energy (Shon $e t$ al., 
2007). There is a noteworthy rise in the production of hulless barley for the diets of non-ruminant animals who are not able to digest the fibrous hulls of the hulled barley and for the food thickeners, health foods and breakfast cereals for the human consumption because it has several nutritional characteristics (Edney et al., 1992). The two different forms of hulless barley are waxy and normal. The amylose to amylopectin ratio in the normal form of hulless barley is similar to the regular hulled barley (around 25\% amylose and 75\% amylopectin). The waxy form of hulless barley has higher content of amylopectin, starch and $\beta$-glucans (about 95 to 100\% amylopectin). Because of higher $\beta$-glucan content, waxy barley is not easier to digest which makes it highly suitable for its use as thickening agents in various industries. Standard hulless barley cultivars possess higher $\beta$-glucan content as compared to its hulled types.

Barley was most probably used in food but progressed mainly into feed, malting grain due to the increase in eminence of rice and wheat. On the other hand, it is essential human nourishment in the areas where hulless barley is developed at much higher frequencies. As of late, it is pulling in significant consideration as a nutritious human sustenance in non-conventional areas because of its higher content of $\beta$-glucan, which go about as inhibitor in the synthesis of cholesterol (Berglung et al., 1993), its higher lysine (Bhatty, 1986), and protein content (Oscarsson et al., 1996) and owing to processing benefits without the removal of hull for the barley food trade (Bhatty, 1993; Newman, 1992). There are likewise ongoing increments in the utilization of naked barley in western nations. Therefore, hulless barley is now used in various kinds of food products and their consumption provides potential health benefits.

\section{Structure of barley grain}

Barley grain primarily comprises of endosperm (75\%), aleurone layer, germ and pericarp. Pericarp and seed coat provide protection to the seed against external injuries by completely covering the entire seed. The fundamental portion of the barley grain is endosperm, the chemical composition of which is straight linked to the quality of malt. The endosperm tissue serves as the reservoir of starch granules whereas the aleurone layer primarily accompanies the significant part of the barley grain. The aleurone layer is made up of the cells that comprise starch granules. It is few celled thicker and encloses the entire endosperm. The aleurone layer is just one cell thicker at the germ and in the crease its thickness is highly variable.The nonstarch polysaccharides, arabinoxylan and $\beta$-glucan are mainly located in the aleurone layer cell wall . However, $\beta$-glucan to arabinoxylan ratio is $25: 75$, which is opposite for the cell wall of endosperm.
The higher the $\beta$-glucan content thicker is the cell wall found in various cultivars (Zheng et al., 2000). The aleurone layer performs an important role in the expression of the degrading enzymes of endosperm during germination, comprising :i) $\beta$-glucanases; ii) Limit Dextrinase (Sissions et al., 1992); iii) $\alpha$-amylase; iv) Proteinases and peptidases (Jones, 2005a); v) a-glucosidase; vi) Inhibitors proteinases (Jones, 2005b), vi) limit dextrinase and trypsin (Macgregor et al., 2002; Stahl et al., 2007).

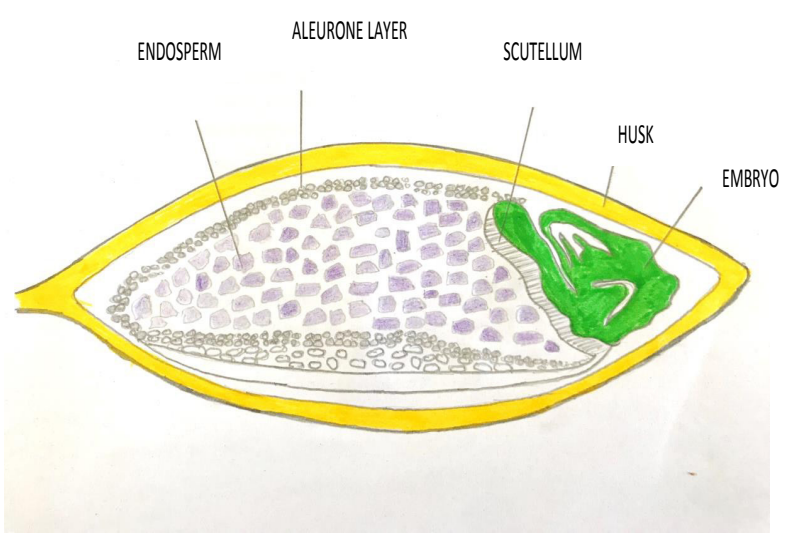

Fig 1: Barley grain structure - Wiring Diagram (rs38. lucia-umami.de)

\section{Barley grain classification and its composition}

Barley can be categorized into six row or two row type, spring or winter type, malting/feed/food type and hulled or hulless type. Hulled barley alludes to covered barley which is slightly processed so as to take off only the outer tough indigestible hull. Hulled barley mightbe bought in various forms comprising cut (grits), ground or flaked (flour or meal), kernels (berries). Hulless barley mentions to a kind of barley in which the intense inedible exterior hull is insecurely bound to the kernel. The exterior hull is so loose to the point

Table 1. Difference in biochemical constituents in hulled and hulless barley

\begin{tabular}{lcc}
\hline S.No. & Hulless barley & Hulled barley \\
\hline 1. Energy (Cal) & 370 & 350 \\
2. Protein (\%) & 13 & 10 \\
3. Carbohydrate (\%) & 73.9 & 78 \\
4. Fat (\%) & 2.2 & 1 \\
5. B-glucan (\%) & 4.1 & 3.9 \\
6. Crude fiber (\%) & 1.4 & 5 \\
7. Calcium $(\%)$ & 5.0 & 2 \\
\hline
\end{tabular}

Source: D. Hickling, Canadian International Grains Institute 

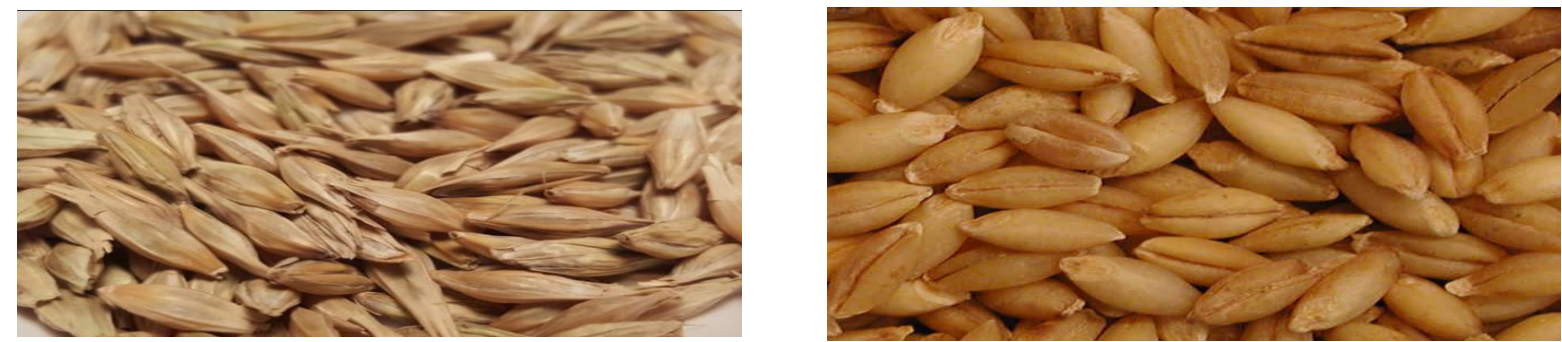

Fig 2: Hulled and hulless germplasm under research trial of Punjab Agricultural University

that, it usually falls off during the harvesting time of the hulless barley.

$\beta$-glucan is significant component which forms the cell wall in barley endosperm which accounts for $75 \%$ of the endosperm cell wall mass. Barley varieties with high $\beta$-glucan content are digested more slowly than standard barley varieties and thus help in weight control programmes. $\beta$-glucans are found to lower the cholesterol level in plasma, to enhance lipid metabolism, to lower the glycemic index and the threat of colon cancer (Ahmad et al., 2012). In barley, there is genetic variation in $\beta$-glucan content the levels of which ranged from $<3.0 \%$ to $>15.0 \%$ (Virkki et al., $2004)$. Barley having the waxy gene showed higher levels of $\beta$-glucans. $\beta$-glucan content is affected by environmental conditions like an increase under dry and hot conditions and a decrease under moist conditions. Starch is the main carbohydrate in barley having the range of $62-77 \%$ of the grain dry weight. It consists of amylose and amylopectin. A higher percentage of amylopectin content leads to an increase in solubility whereas high content of amylose lowers the digestibility of starch because the amylose content and the resistant starch formation are positively correlated with each other (Singh et al., 2010). Barley endosperm protein has high reserves of the prolamin (around 50\%) storage proteins that have adequate nutritive quality with protein efficiency ratio ranging be around 2.04 with the three other proteins globulins, albumins and glutelins making up the rest of the protein (Newman and McGuire, 1985). The protein synthesis begins somewhat early after anthesis, in spite of the fact that there are distinctive reports on the definite timing of these protein constituents.

\section{Potential opportunities}

Hulless barley is a multi-purpose cereal crop grown for food, malting and general purposes (feed) throughout the world (Table 2). Hulless, barley with its high level of digestible energy for feeding or higher levels of malt extract for fermenting has constantly fascinated end users of barley. Its nutritional significance for monogastric animals has been realized only recently. Barley is the main cereal utilized in the malt production throughout the world because it contains numerous enzymes which are essential for transforming the grain starches into several types of sugars like glucose (monosaccharide), maltose (disaccharide), maltotriose (tri-saccharide) and the complex sugars known as maltodextrines. It also contains additional enzymes, for instance proteases, which causes the protein breakdown in the grain into different forms that can be exploited by yeast. Therefore, malted barley grain is employed in the beer production, malted milk shakes, malt vinegar, whisky, confections like malsters and whoppers, flavored drinks like Horlicks, milo and ovaltine and some baked goods. For the ruminants, barley is the third highly promptly degradable cereal after wheat and oats. Whereas, relatively lesser amount of barley is utilized precisely for food nowadays, it has incredible prospective to regain some of its importance as a food grain, mainly because of its high nutritive esteem. Hulless barley grain offers lesser fat complex sugars primarily starch for vitality, comparatively welladjusted protein content to meet amino acid necessities, vitamins, mainly vitamin $\mathrm{E}$, minerals and various other antioxidants, mainly polyphenolics, and soluble and insoluble fiber with general (quick passage of food through colon) and definite health benefits. So there are various potential opportunities of barley like malting, food and feed purposes and the prospective is great to progress barley for all these practices.

4.1 Malting/Brewing: Regardless of the accessibility of hulless barley cultivars with remarkable ability of malt quality, commercial demand has been constrained. Large commercial malsters and brewers stay suspicious because of potential processing concerns, for instance stickiness of hulless barley

Table 2. Proportionate utility of barley

\begin{tabular}{lc}
\hline \multicolumn{1}{c}{ Various fields } & Utility $(\%)$ \\
\hline 1. Brewing purpose & $50 \%$ \\
2. Food and feed purpose & $25 \%$ \\
3. Distilled and whisky & $20 \%$ \\
4. Syrup, Vinegar, Diuretics & $5 \%$ \\
\hline
\end{tabular}

Source:Vasan A et al., 2014 
during processing and acrospires loss. The brewing industry has spent years developing barley varieties that perform well in the traditional brewing process and give them the results they want. CDC clear is a hulless malting barley variety used by various malsters in malting industries. It is unlikely they would be very open to moving to other varieties, such as hulless barley without a very compelling economic incentive for them to do so. Malting barley varieties are for the most part produced for a particular market e.g. for trade or domestic brewing. The chemical, biochemical and physical properties of barley grain can largely affect the malting procedure and beer quality . Kernel physical features like germ growth, kernel maturity, germination percentage, size, frost damage and measure of seed borne maladies are elements that influence malting process. The measure of grain protein, $\beta$-glucan, starch and their interactions in the period of grain filling influence grain hardness and yield of malt extract (Psota et al., 2007). Another factor that defines the quantity of malt extract is the level of alpha amylase. Soft barley varieties are usually preferred for malting (Gupta et al., 2010 ) with protein content ranging from $10.5-13.0 \%$ for six-row varieties and $10.5 \%-12.5 \%$ for two-row types. Barley cultivars having higher protein concentration $(>15 \%)$ are not used for malting because it needs longer steeping time, produces low malt extracts and has erratic germination (Swanston and Molina-Cano, 2001). Bleached barley grain is additionally not suitable for malting because during the breakdown of phenolics, the production of undesirable flavors takes place in lager (Mussatto et al., 2006). An effective maintenance of malting barley trade market wants great determination of cultivars with suitable malting qualities.

4.2 Livestock feed: Hulless barley is regularly utilized for animal feed in spite of the fact that nutritive value is lesser as compared to wheat or corn. Both six- and tworow hulless barley are usually grown for the production of animal feed. The removal of the hull is required to result in uncertain increments in absolute nutrient levels of hulless barley when compared with regular barley. In practice, the nutrient composition of hulless barley often exceeds this expectation. That's why the interest is growing towards the developing of hulless barley for the feed industry. The six- and two-row hulless barley produced for feed in Canada are moderately higher in protein content (14-15\%), however the two-row barley grain is favored because it has a relatively higher content of carbohydrates (Fregeau-Reid et al., 2001) and is highly edible by monogastric animals like swine and poultry. There may be a potential to use hulless barley as sprouted fodder.

The primary advantage of sprouted fodder in contrast to feeding grain is "enhanced sugar, starch and protein" profile. Almost majority of the starch present in the grain is changed over to sugar by sprouting which is preferably used by the rumen over the dry grain. This lessens the acidosis issue, as the rumen $\mathrm{pH}$ remains more constant without the consistent input of starch, vitamin and mineral levels in hydroponically sprouted barley are considerably enhanced over those in grain; moreover, they are assimilated more proficiently because of the absence of inhibitors of the enzymes in sprouted grain. Sprouts give great supply of various vitamins like $\mathrm{A}, \mathrm{E}, \mathrm{C}$ and $\mathrm{B}$. The levels of vitamin in certain seeds can increment upto 20 times than their original value within some days of sprouting. Barley grows the fastest, sprouts the bests and is highly cost efficient in tremendous experiments contrasted with oats and wheat.

When the monogastric animals are fed with hulled barley they will not be able to digest the fibrous hull therefore to help in digestion, an enzyme named $\beta$-glucanase is often supplemented with the diet of these animals (Mathlouthi et al., 2003). Other than hulls, an additional component of seed is phytate that adversely influence barley consumption as animal feed. Phytic acid effectively chelates polyvalent cations like copper, iron, calcium, magnesium, zinc and aluminium therefore making the minerals inaccessible for absorption (Adams et al.,2002). Zinc is one of the most vulnerable mineral to chelation by phytic acid. A decrease of phytic acidformation in barley genotype HB379 (Roslinsky et al., 2007) has multiplied the accessibility of zinc and phosphorous for broilers (Linares et al., 2007). Decrease in milk fat content is found when barley with high starch concentration is utilized as feed for lactating bovines (Larsen et al., 2009). For that reason, it is essential to examine seed constitution while choosing barley grain for ruminants as well as non-ruminants.

4.3 Food: Nowadays numerous diseases are spreading at much faster rate. Mostly the young generation does not have much responsiveness about healthy nourishing supplements. The crude protein content is higher but crude fiber content is lower in hulless barley as compared to hulled barley because hull comprises large percentage of kernel crude fiber content. It also comprises higher content of a polysaccharide named $\beta$-glucan, which is more desirable when barley is grown for food purposes. For this reason, hulless varieties are being developed primarily for use as human food. Based on nutrition point of view, hulless barley is winner as compared to hulled barley. This centuriesold grain is rich in fiber, comprises essential minerals and vitamins, lower in fat content as well as cholesterol free. Therefore, hulless barley is preferred nowadays in foods. 
4.3.1 Cholesterol free: Due to the absence of cholesterol in hulless barley, doctors recommend to eat barley food to the heart patients.Although barley is cholesterol free but it also possess cholesterol lowering property and hence create hypocholestrolemic effects inside the body. Soluble dietary fiber $\beta$-glucan helps in the absorption and elimination of bile acids formed from the cholesterol present in the liver. The bile acids absorption activates the liver to make more bile acids from the cholesterol (Brennan, 2005) and the net impact is a decrease in cholesterol level of blood (Behall, 2004). Barley fiber is additionally an excellent source of vitamin B (niacin) that decreases platelet aggregations which are accountable for the formation of blood clots and declines the total cholesterol level, lipoprotein as well as free radicals that causes the oxidation of LDL cholesterol. Therefore, niacin secures against various cardiovascular diseases (Jood and Kalra, 2001). Various studies have demonstrated that soluble fiber $\beta$-glucan from barley and oat can bring down the LDL and total cholesterol level and therefore play an vital role in both the anticipation and administration of cardiovascular ailment. The FDA established that every-day utilization of $3 \mathrm{~g}$ of soluble dietary fiber $\beta$-glucan from barley or specific dry milled barley produces would create a similar cholesterol-bringing down impact as oat products (decreasing total plasma cholesterol level by $5-8 \%$ ).

4.3.2 High content of vitamins and minerals: Hulless barley is also a principal source of various vitamins and minerals like niacin, thiamine, selenium, iron, magnesium, zinc, phosphorous and copper. The mineral content of barley kernel varies from $2-3 \%$, depending on the genotype (Owen et al., 1977). The minerals present in the seed are mainly found in the aleurone, embryoas well as in pericarp tissues (Marconi et al., 2000). Phosphorous plays a vital role in forming the mineral matrix of bone and also helps in the formation of several life critical compounds comprising adenosine triphosphate (ATP: which is the energy currency of body). Phosphorous is the main component of nucleic acids which are the building blocks of genetic code.

Zinc helps to heal injuries and also works wonders for the skin whereas selenium plays a major role in lowering the chances of colon cancer. Selenium additionally plays an important role in several metabolic pathways: antioxidant defense systems, immune function and thyroid hormone metabolism. Selenium has been appeared to initiate DNA repair and amalgamation in damaged cells, to hinder the cancer cells proliferation, and to prompt their apoptosis, which is the self-destruct property the body utilizes to remove abnormal or wornout cells. Copper is another trace element provided by barley, which is helpful in lessening the signs of rheumatoid arthritis. Copper is an important cofactor of crucial oxidative enzyme named superoxide dismutase (SOD). SOD deactivates free radicals which are formed in mitochondria.

\subsubsection{High levels of antioxidants and} phytochemicals: Phenolics are one of the major class of phytonutrients and these are potent antioxidants that works in numerous ways to prevent diseases. These are secondary metabolites of plants having probable optimistic physiological effects (Peng et al., 2015). Various compounds are incorporated in this category for example ellagic acid, curcumin, catechins, quercetin and many more. Barley grains comprise a varied range of phenolic acids that are derivatives of cinnamic acid or benzoic acid, flavones, flavanones, chalcones, proanthocyanidins and flavonols (Hernanz et al., 2001).These phenolic compounds are the important bioactive components having high health promoting activity which are utilized in food products to rise the levels of dietary fiber and nutraceutical properties. These compounds are mainly located in the pericarp of cereal grains affecting their appearance, taste and odour in the plant foods. In cereals they can exist in free or bound form. Bound phenolic compounds are usually ester linked with the cell wall polymers present in the external layers of barley kernel. An important phenolic compound present in cereals in bound form is ferulic acid and its dehydro dimer derivatives (Kim et al., 2007). In general, larger amounts of phenolic compounds were accounted for oat and barley contrasted with rye and wheat (Zielinski and Kozlowska, 2000). The phenolic acid which is present in large amounts in cereals is ferulic acid, signifying up to $90 \%$ of overall polyphenols (Sosulski et al., 1982). Similarly, Naczk and Shahidi (2006) and Hernanz et al. (2001) stated that ferulic acid is the principal phenolic acid present in barley grain. Yu et al. (2002) examined the phenolic acids composition in thirty barley cultivars where they establish changing levels of cinnamic and benzoic acids. Phenolic compounds are thought to exhibit several roles like: reducing agent, free radical scavenger and prevents the formation of singlet oxygen and potential producer of pro-oxidant metals.

Anthocyanins present in hulless barley are discovered either in the aleurone layer or the pericarp bring about blue and purple hues of grain colour. The black coloration of the pericarp and lemma of barley is depicted because of the presence of melanin-like pigment in them (Lundqvist et al., 1996) which might overlap additional pigments. The black colour of the kernel is because of melanin-like pigment is unidentified to wheat cultivars. 
Zeaxanthin and lutein are the two fundamental carotenoids recognized in hulless barley (Panfili et al., 2004). They effectively functions as free radical scavengers because of the presence of electron rich chain (Cooke et al., 2002) and hinder the free radical propagation reactions for example lipid peroxidation. Zeaxanthin and lutein are accountable for the pigmentation of the macula lutea present in retina, which is the area of best visual sharpness. Therefore, dietary zeaxanthin and lutein are thought to provide protection against cataract and age-related macular deterioration (Beatty et al., 2000). Moreover, zeaxanthin and lutein probably act together with various other bioactive components against cardiovascular risk, cancer and different infections (Mares-Perlman et al., 2002; Calvo, 2005). Tocopherols or vitamin E are additionally present in noticeable amounts (Cavallero et al., 2004; Andersson et al., 2008). Another kind of phytonutrient rich in barley are plant lignans, that are transformed by friendly flora present in digestion tracts into the mammalian lignans, comprising one known as enterolactone that is supposed to provide protection against breast and various hormone dependent cancers along with heart disease.

4.3.4 Hypoglycemic effect: Hulless barley $\beta$-glucan in their native form, are high sub-atomic weight polysaccharides that display higher viscosities at lesser concentrations (Ren et al., 2003). Intake of viscous polysaccharides causes an increase in meal bolus viscosity in the stomach, which ultimately reduces the blending of food with peptic enzymes and therefore delays gastric purging (Marciani et al., 2001). Greater viscosity also slows down the glucose absorption (Braaten et al., 1991; Panahi et al., 2007). In vitro digestion studies show that $\beta$-glucan reduces the rate of starch degradation (Regand et al., 2011).

4.3.5 Used as Prebiotic: Prebiosis involves in the particular incitement of activity and growth of single or a restricted number of valuable micro-organisms in the gut microbiota, therefore increasing probiotic inferring medical advantages to the host (Mayo et al., 2008; Roberfroid et al., 2010). In addition, prebiotic properties have been identified with enhanced efficiency in immune functions, tumor prevention, intestinal functions and mineral absorption (Dass et al., 2007; Xiong et al., 2004; Artis, 2008). The gut micro-organisms include generally anaerobic bacteria that require fermentative substrates to get metabolic vitality for their activity and development. Non-edible food carbohydrates, containing fibres, resistant starch, oligosaccharides in addition to peptides or proteins that get away from human digestion, can be used by microbes as an energy source (Topping and Clifton, 2001; Lupton, 2004). Numerous food components, together with galacto-oligosaccharides (GOS) and fructo-oligosaccharides (FOS) have been presented to positively impact the metabolism and development of lactobacilli and bifidobacteria, along with the general composition of the gut micro-organisms, therefore playing out a prebiotic activity. Amongst dietary fibres, $\beta$-glucans, accompanied by other indigestible food constituents such as lactosucrose, isomaltooligosaccharides and soybean oligosaccharides, are presently being examined to assess their possible prebiotic impacts.

$\beta$-Glucans comprise the water-soluble portion of numerous cereals and these are present in the aleurone cell wall as well as sub-aleurone layer of sorghum, barley, triticale, rice, wheat and oat (Mayo et al., 2011, Holteljolen et al., 2006). Cereals (like barley and oat) with higher $\beta$-glucan level, the content of which lies in the range of $3-8 \mathrm{~g}$ and $2-20 \mathrm{~g}$ per $100 \mathrm{~g}$ of dry weight, respectively. These cereal grain $\beta$-glucans are linear polymers of D-glucose connected by $\beta(1,3)$ or $\beta(1,4)$ glycosidic linkages, for which individuals do not have enzymes to break these glycosidic linkages, and introducing side branches connected to the main chain by $\beta(1,2)$ - or $(1,6)$-glucopyranosyl units (El Khoury et al., 2012; Barsanti et al., 2011). In addition, $\beta$-glucans have been appeared to be exceptionally fermentable by the intestinal micro-organisms of colon and caecum and can improve the development rate and the production of lactic acid of micro-organisms sequestered from the human intestine (Blaut, 2002; Kedia et al., 2008).

4.3.6 Prevents osteoporosis: Barley is considered as an excellent source of silicon, which is an important mineral in bone formation (Nielsen and Sandstead, 1974). High silicon content has been found in beer due to the processing of barley. In 1970, Edith M. Carsile, Ph.D., in print a brief paper in discipline of science entitled "Silicon: a possible factor in bone calcification" (Carlisle, 1970). Silicon binds with glycosaminoglycans and plays a major role in the development of crossconnects between proteoglycans and collagen (Carlisle, 1981). Silicon is found in all body tissues, but the most elevated silicon content was found in the bones and in various connective tissues like skin, arteries, hair and nails (Jugdaohsingh, 2007). In vitro studies have established that silicon activates osteoblast differentiation and synthesis of type I collagen (Reffitt $e t$ al., 2003). Studies in rats have established that silicon at physiological levels increases the absorption of calcium in bone as compared to the rats that are silicon deficient (Seaborn and Nielsen, 2002). Therefore, silicon is an important element for the bones formation. The precise mineralization sequence is not known, however Carlisle established that silicon most likely acts by making the bone lattice more calcifiable (Carlisle, 1981). The 
concentration of silicon in osteoid is 25 times greater as compared to the surrounding regions and silicon concentration slowly decreases as calcification takes place (Carlisle, 1970). Additional investigation in postmenopausal animal models utilized elevated levels of supplementary dietary silicon $(20 \mathrm{mg} / \mathrm{kg} /$ day) (Bae et al., 2008; Kim, 2009). These higher levels of silicon stimulate bone formation, lesser calcium defecation in the urine and elevated bone mineral density.

4.3.7 Keeps intestine healthy: Hulless barley is an exceptional well spring of fiber that keeps human body toxin free. Barley grass is lavish in dietary fiber which acts as an energy source to the benevolent bacteria present in our large intestine. The fiber present in barley is fermented by these bacteria and leads to the production of butyric acid which acts as principal fuel for the intestinal cells. It is highly effective in keeping up a sound colon. By maintaining the intestine in good health, it helps to reduce the movement time of faeces and furthermore keeps the stomach hygienic. It significantly decreases the risk of colon malignancy as well as hemorrhoids.

4.3.8 Protects against gallstones: Hulless barley efficiently enables women abstain from developing gallstones. As it contains higher content of insoluble fiber, it really encourages people decrease bile acid discharge, in this manner escalating insulin sensitivity and decreasing the triglyceride amount. An article in the American Journal of Gastroenterology states that intake of a fibrous diet by women have 17\% lesser possibility of gallstones development when compared with other women.

\section{Current research}

Much is investigated about the nourishing and medical advantages of barley intake but lesser is known about the usefulness of barley grain constituents in terms of processing and food items development. Examining the health benefits of $\beta$-glucan and phenolic compounds present in barley, the human consumption of barley is empowered by using it in foods with attractive sensory attributes. Attempts have been made to use barley in bread, cookies, noodles and in chapattis. Studies have also been undertaken to access transcriptome changes during the development of hulless barley grain which is not surely understood yet.

5.1 Use of hulless barley in improving the nutritional value of biscuit and chapatti prepared from wheat flour: A great attention has newly ascended in the improvement of 'functional' foods, items that may offer health benefits further than the conventional supplements. Foods that contain high cancer preventive agents and a lower glycemic index (GI) can lower the threat of high postprandial oxidative stress, which is one of the components of the beginning of numerous long lasting diseases (Hou and Jimenez, 2013). Barley is examined as extremely nutritive cereal grain due to the presence of higher content of $\beta$-glucan soluble fiber (Sullivan et al., 2013) in addition to some cancer preventive agents (Zhao et al., 2008). Studies additionally demonstrate that bread prepared with a combination of barley and wheat flour has suitable sensory characteristics (Skendi et al., 2010). The $\beta$-glucan present in barley flour can improve the bread quality by altering the insulin and glycemic response (Gujral and Gaur, 2005). Barley is mostly being utilized to prepare beer and malt. Barley is additionally utilized in high fiber content biscuits, multigrain flours, muesli and breakfast cereals which can be instantly consumed. At home, barley flour can be effectively mixed with the wheat flour keeping in mind the end goal to make more nutritive and healthy items for daily utilization.

Narwal et al. (2017) made first effort to utilize a hulless barley genotype (BHS 352) for mixing with the wheat flour (C 306 \& HS 490) and making mixed chapatti and cookies. These foodstuffs were then evaluated for total phenolic, $\beta$-glucan content and antioxidant activity to note the mixing effects. Their investigation has demonstrated that addition of barley to wheat biscuit and chapatti can extensively improve the nutritive significance of these items in terms of higher $\beta$-glucan content, high phenolic content and antioxidant activity. Besides, hulless barley requires minimal processing when contrasted with hulled barley and hence substantially more beneficial for blending motive at house hold level. Therefore, BHS 352, which is a hulless barley variety, can be decent choice to enhance the health and nutritional advantages of wheat-based items. By integrating barley flour into commonly utilized wheat-based items, it could benefit consumers to enhance their wellbeing.

5.2 Transcriptome changes during the development of barley grain utilizing Illumina-paired end RNA sequencing: Hulless barley, with its exclusive nutritious esteem and possible medical advantages, has progressively pulled in considerations in current years. Though, the transcription changes during development of hulless barley grain are not surely knew. Tang et al. (2017) examined the transcriptome changes throughout the development of barley grain of two Tibetan hulless barley varieties 08-1127(C2) and Zangqing 2000(Q) with the different starch synthesis characteristics, and then relative transcription methodology in these genotypes was accomplished by means of Illumina paired-end RNA-sequencing. Co-modulated and genotype-specific differentially expressed genes were recognized and functionally interpreted, and their expression levels accumulated in various KEGG 
pathways were additionally carried out. They further analysed the genes related to starch synthesis in these two phenotypes and authenticated by quantitative real-time PCR. This investigation provides plentiful resources for detection of genes which are related to starch synthesis and are also essential for quality enhancement in barley.

\section{Conclusion and implications}

There are greater opportunities for hulless barley in the food for human consumption than in the malting/ brewing area. There are several reasons behind this like hulless barley has several benefits over hulled barley in storage, shipping and processing. The removal of hull fraction enhances the bulk density (weight/volume) when compared with hulled barley by approximately $25 \%$, which will lead to huge cost saving. In case of hulless barley minimal processing is required because there is no need to remove the hull due to which it could be directly used for human consumption. Barley in general is not genetically modified so can be used in a wide variety of products without having to worry about trade barriers or consumer distrust of genetically modified ingredients. Hulless barley is known for its superior nutritional components like starch, protein, total dietary fiber, $\beta$-glucan and limiting amino acids as compared to its hulled genotypes. The $\beta$-glucan of barley prevents an increase in the LDL cholesterol levels and it also regulates glucose metabolism which helps in regulating type 2-diabetes. Due to the presence of high phenolics content in hulless barley, it serves as potential antioxidant and therefore doctors recommend the diet containing barley. The eventual fate of hulless barley for malt was given a lift when the malting industry demonstrated high concentrates was their main interest in hulless barley malt. They recommended breeder's to restricts their quality purposes to decreasing wort $\beta$-glucan, decreasing adhering hulls, lowering protein content of grain and increasing malt extract. Currently hulless barley is used as feed as diet of non-ruminants as they are not able to digest fibrous hull of hulled barley. Exploitation of barley in baked goods for example breads, chapattis and cookies can also open a way to utilize the health welfares of barley in food.

\section{References:}

1. Adams CL, M Hambidge, V Raboy, JA Dorsch, L Sian, JL Westcott and NF Krebs. 2002. Zinc absorption from a low-phytic acid maize. American Journal of Clinical Nutrition 76: 556-559.

2. Ahmad A, FM Anjum, T Zahoor, H Nawaj and SM Dilshad. 2012. $\beta$-glucan: a valuable functional ingredients in foods. Critical Review of Food Science and Nutrition 52: 2011-2012.
3. Andersson AAM, AM Lampi, L Nystrom, V Pironen, L Li, JL Ward, K Begruers, CM Courtin, JA Delcour, D Boros, A Fras, W Dynkowska, M Rakszegi, Z Bedo, PR Shewry and P Aman. 2008. Phytochemical and dietary fiber components in barley varieties in the healthgrain diversity screen. Journal of Agricultural and Food Chemistry 56: 97679776.

4. Anonymous 2017. Indian Institute of Wheat and Barley Research Annual Report 2016-17, Karnal, India. 152p.

5. Artis D. 2008. Epithelial-cell recognition of commensal bacteria and maintenance of immune homeostasis in the gut. Nature Reviews Immunology 8: 411-420.

6. Assefa A and MT Labuschagne. 2004. Phenotypic variation in barley (Hordeum vulgare L.) landraces from NorthShewa in Ethiopia. Biodiversity Conservation 13: 1441-1451.

7. Bae Y J, JY Kim, MK Choi, YS Chung and MH Kim. 2008. Short term administration of watersoluble silicon improves mineral density of the femur and tibia in ovariectomized rats. Biological Trace Element Research 124: 157-163.

8. Barsanti L, V Passarelli, V Evangelista, AM Frassanito and P Gualtieri. 2011. Chemistry, physico-chemistry and applications linked to biological activities of $\beta$-glucans. Natural Product Reports 28: 457-466.

9. Beatty S, H Koh, M Phil, D Henson and M Boulton. 2000. The role of oxidative stress in the pathogenesis of age-related macular degeneration. Survey of Ophthalmology 45: 115-134.

10. Behall KM, DJ Scholfield and J Hallfrisch. 2004. Diets containing barley significantly reduce lipids in mildly hypercholesterolemic men and women. Ammerican Journal of Clinical Nutrition 80: 11851193.

11. Berglung PT, ET Holm and CE Fastnaught. 1993. Hulless barley: alternative uses. Barley Neresletter 36: $130-131$.

12. Bhatty RS. 1986. The potential of hull-less barley, a review. Cereal Chem 63: 97-103.

13. Bhatty RS. 1993. Physicochemical properties of roller-milled barley bran and flour. Cereal Chemistry 70: 397-402.

14. Blaut M. 2002. Relationship of prebiotics and food to intestinal microflora. European Journal of Nutrition 41: i11-i16

15. Boros D, B Rek-Cieply and M Cyran. 1996. A note on the composition and nutritional value of hulless barley. Journal of Animal Feed Science 5: 417-424. 
16. Braaten JT, PJ Wood, FW Scott, KD Riedel, LM Poste and MW Collins. 1991. Oat gum, a soluble fiber which lowers glucose and insulin in normal individuals after an oral glucose load: comparison with guar gum. Ammerican Journal of Clinical Nutrition 53: 1425-1430.

17. Brennan CS. 2005. Dietary fiber, glycemic responses and diabetes. Molecular Nutrition and Food Research 49: 560- 568.

18. Calvo MM. 2005. Lutein: A valuable ingredient of fruit and vegetables. Critical Review of Food Science and Nutrition 45: 671-696.

19. Carlisle EM.1970. Silicon: a possible factor in bone calcification. Science 167: 279-280.

20. Carlisle EM.1981. Silicon: a requirement in bone formation independent of vitamin D1. Calcified Tissue International 33: 27-34.

21. Cavallero A, A Gianinetti, F Finocchiario, G Delogu and AM Stanca. 2004. Tocols in hull-less and hulled barley genotypes grown in contrasting environments. Journal of Cereal Science 39: 175-180.

22. Choo TM, KM Ho and RA Martin. 2001. Genetic analysis of a hulless $\times$ hulled cross of barley using a double haploid lines. Crop Science 41: 1021-1026.

23. Cooke MS, MD Evans, N Mistry and J Lunec. 2002. Role of dietary antioxidants in the prevention of invivo oxidative DNA damage. Nutrition Research Reviews 15: 19-41.

24. Dass NB, AK John, AKBassil, CW Crumbley, WR Shehee, FP Maurio, GBT Moore, CM Taylor and GJ Sanger. 2007.The relationship between the effects of short-chain fatty acids on intestinal motility invitro and GPR43 receptor activation. Neurogastroenterology and Motility 19: 66-74.

25. Duffus CM and MP Cochrane. 1992. Grain Structure and Composition. In: Shewry P R (eds.) Barley: Genetics, Biochemistry, Molecular Biology and Biotechnology. CAB International axon, 291318.

26. Duffus CM and Cochrane MP. 1993. Formation of the Barley Grain - Morphology, Physiology and Biochemistry. In: MacGregor A W, Bhatty R S (eds.) Barley Chemistry and Technology. AACC, Minnesota, 31-72.

27. Dusabenyagasani M, D Perry, T Lewandoski and T Demeke. 2003. Genotyping Canadian malting barley varieties with SNP markers. Plant \& Animal Genomes XI Conference. January 11-15, 2003.

28. Edney M, R Tkachuk and AW MacGregor. 1992. Nutrient composition of hull-less barley cultivar, condor. Journal of Science Food and Agriculture 60: 451-456.
29. El Khoury D, C Cuda, BL Luhovyy and GH Anderson. 2012. Beta glucan: Health benefits in obesity and metabolic syndrome. Journal of Nutrition and Metabolism 2012: 851362.

30. FAOSTAT. 2018. Food and Agriculture Organization Corporate Statistical Database. http://www.faostat.fao.org/.

31. Fregeau-Reid J, Thin-Meiw Choo, Keh-Ming Ho, RA Martin and T Konishi. 2001. Comparisons of two-row and six-row Barley for chemical composition using doubled haploid lines. Crop Science 41: 1737-1743.

32. Gujral HS and S Gaur. 2005. Instrumental texture of chapatti as affected by barley flour, glycerol monostearate and sodium chloride. International Journal of Food Properties 8: 1-9.

33. Gupta M, N Abu-Ghannam and E Gallaghar. 2010. Barley for brewing: Characteristic changes during malting, brewing and applications of its by-products. Comprative Review of Food Science F 9: 318-328.

34. Hernanz D, V Nunez, AI Sancho, CB Faulds and G Williamson G. 2001. Hydroxycinnamic acids and ferulic acid dehydrodimers in barley and processed barley. Journal of Agricultural and Food Chemistry 48: 4884-8488.

35. Holtekjolen AK, AK Uhlen, EBrathen, S Sahlstrom and SH Knutsen. 2006. Contents of starch and non-starch polysaccharides in barley varieties of different origin. Food Chemistry 94: 348-358.

36. Hou GG, and V Jimenez. 2013. Developing barley-fortified wheat based foods. http://www. barleyfoods.org/documents/barleybagelsbw. pdf Accessed 16 September 2013.

37. Jones BL. 2005a. Endoproteases of Barley and Malt. Journal of Cereal Science 42: 139-156.

38. Jones BL. 2005b. The Endogenous endoprotease inhibitors of barley and malt and their roles in maltingand brewing. Journal of Cereal Science 43: 271-280.

39. Jood S and S Kalra. 2001. Chemical composition and nutritional characteristics of some hull less and hulled barley cultivars grown in India. Nahrung 45: 35-39.

40. Jugdaohsingh R. 2007. "Silicon and bone health". Journal of Nutrition Health and Aging 11: 99-110.

41. Kedia G, JA Vazquez and SS Pandiella. 2008. Evaluation of the fermentability of oat fractions obtained by debranning using lactic acid bacteria. Journal of Applied Microbiology 105: 1227-1237

42. Kim MH, YJ Bae, MK Choi and YS Chung. 2009. Silicon supplementation improves the bone mineral density of calcium-deficient ovariectomized rats by 
reducing bone resorption. Biological Trace Element Research 128: 239-247.

43. Larsen M, P Lund, MR Weisbjerg and T Hvelplund. 2009. Digestion site of starch from cereals and legumes in lactating dairy cows. Animal Feed Science and Technology 153: 236-248.

44. Linares LB, JN Broomhead, EA Guaiume, DR Ledoux, TL Veum and V Raboy. 2007. Effects of low phytate barley (Hordeum vulgare L.) on zinc utilization in young broiler chicks. . Poultry Science 86: 299-308.

45. Lu LS .1995. Chinese Hordeum vulgare. China Agriculture Press, Beijing, pp 138-141.

46. Lundqvist U,JD Franckowiak and T Konishi. 1996. New and revised descriptions of barley genes. Barley Genetics Newsletter 26: 22-516.

47. Lupton J. 2004. Microbial degradation products influence colon cancer risk: The butyrate controversy. Journal of Nutrition 134: 479-482.

48. MacGregor AW, SL Bazin and SW Schroeder. 2002. Effect of Starch Hydrolysis Products on the determination of Limit Dextrinase Inhibitors in Barley and Malt. Journal of Cereal Science 35: 17-28.

49. Marciani L, PA Gowland, RC Spiller, P Manoj, RJ Moore, P Young and AJ Fillery-Travis. 2001. Effect of meal viscosity and nutrients on satiety, intragastric dilution, and emptying assessed by MRI. Ammerican Journal of Physiology Gastrointestinal and Liver Physiology 280: 1227-1233.

50. Marconi E, M Graziano and R Cubadda. 2000. Composition and utilization of barley pearling by-products for making functional pastas rich in dietary fiber and $\beta$-glucans. Cereal Chemistry 77: 133-139.

51. Mares-Perlman JA, AE Millen, TL Ficek and SE Hankinson. 2002. The body of evidence to support a protective role for lutein and zeaxanthin in delaying chronic disease. Overview. Journal of Nutrition 132: 518-524.

52. Mathlouthi N, H Juin and M Larbier. 2003. Effect of xylanase and $\beta$-glucanase supplementation of wheat-or wheat- and barley-based diets on the performance of male turkeys. British Poultry Science 44: 291-298.

53. Mayo B, D van Sinderen and M Ventura. 2011. Genome analysis of food grade lactic acidproducing bacteria: From basics to applications. Current Genomics 2008: 169-183.

54. Mussatto SI, G Dragone and IC Roberto. 2006. Brewers 'spent grain: generation, characteristics and potential application. Journal of Cereal Science 43: $1-14$.
55. Naczk M and F Shahidi. 2006. Phenols in cereals, fruits and vegetables. Occurrence, extraction and analysis. Journal of Pharmacy and Biomedical Analysis 41: 1523-1542.

56. Narwal S, D Kumar, S Sheoran, RPS Verma and RK Gupta. 2017. Hulless barley as a promising source to improve the nutritional quality of wheat products. Journal of Food Science and Technology 54: 2638-2644.

57. Newman RK. 1992. Nutritional quality. In: Munck L (ed) Sixth barley genetics symposium. Helsingborg, Sweden 2: 940-944.

58. Newman CW and CF McGuire. 1985. Nutritional quality of barley. In: Rasmusson D C (Ed) Barley: Agronomy monograph No. 26. American Society of Agronomy, Crop Science Society of America, Social Science Society of America, Madison, WI, 403-456.

59. Nielsen FH and HH Sandstead. 1974. "Are nickel, vanadium, silicon, fluorine and tin essential for man? A review. Ammerican Journal of Clinical Nutrition 27: 515-520.

60. Oscarsson M, R Andersson, AC Salomonsson and P Aman. 1996. Chemical composition of barley samples focusing on dietary fibre components. Journal of Cereal Science 24: 161-170.

61. Owen BD, D Sosulski, KK Wu and JJ Farmer. 1977. Variation in mineral content in Saskatchewan feed grains. Candian Journal of Animal Science 57: 679-687.

62. Panahi S, A Ezatagha, F Temelli, T Vasanthan and V Vuksan. 2007. $\beta$-glucan from two sources of oat concentrates affect postprandial glycemia in relation to the level of viscosity. Journal of Ammerican College of Nutrition 26: 639-644.

63. Panfili G, A Fratianni and M Irano. 2004. Improved normal phase high-performance liquid chromatography procedure for determination of carotenoids in cereals. Journal of Agricultural and Food Chemistry 52: 6373-6377.

64. Peng XR, JQ Liu, CF Wang, ZH Han, Y Shu, XY Li, HH Zhou and M Qiu. 2015. Unusual prenylated phenols with antioxidant activities from Ganoderma cochlear. Food Chemistry 171: 251-257.

65. Psota V, K Vejrazka, O Famera and M Hrcka. 2007. Relationship between grain hardness and malting quality of barley (Hordeum vulgare L.). Journal of the Institute of Brewing 113: 80-86.

66. Reffitt DM, N Ogston, Jugdaohsingh et al. 2003. Orthosilicic acid stimulates collagen type I synthesis and osteoblastic differentiation in human osteoblast-like cells invitro. Bone 32: 127-135.

67. Regand A, Z Chowdhury, SM Tosh, TMS Wolever and P Wood. 2011. The molecular weight, solubility and viscosity of oat beta-glucan affect 
human glycemic response by modifying starch digestibility. Food Chemistry 129: 297-304.

68. Ren Y, PR Ellis, SB Ross-Murphy, Q Wang and PJ Wood. 2003. Dilute and semi-dilute solution properties of (1-3) (1-4)- $\beta$-D-glucan, the endosperm cell wall polysaccharides of oats (Avena sativa L.). Carbohydrate Polymers 53: 401-408.

69. Roberfroid M, GR Gibson, L Hoyles, AL McCartney, R Rastall, I Rowland, D Wolvers, B Watzl, H Szajewska, B Stahl, F Guarner, F Respondek, K Whelan, V Coxam, MJ Davicco, L Leotoing, Y Wittrant, NM Delzenne, PD Cani, AM Neyrinck and A Meheust. 2010. Prebiotic effects: Metabolic and health benefits. British Journal of Nutrition 104: 1-63.

70. Roslinsky V, PE Eckstein, V Raboy, BG Rossnagel and GJ Scoles. 2007. Molecular marker development and linkage analysis in three low phytic acid barley (Hordeum vulgare) mutant lines. Molecular Breeding 20: 323-330.

71. Seaborn CD and FH Nielsen. 2002. Dietary silicon and arginine affect mineral element composition of rat femur and vertebra. Biological Trace Element Research 89: 239-250.

72. Shon M, DS Himmelsbach, EF Barton, CA Griffey, WS Brooks and KB Hicks. 2007. Near-infrared analysis of ground barley for use as a feedstock for fuel ethanol production. Applied Spectroscopy 61: 1178-1183.

73. Singh J, A Dartois and L Kaur. 2010. Starch digestibility in food matrix: A review. Trends in Food Science and Technology 21: 168-180.

74. Sission MJ, RCM Lance and DHB Sparrow. 1992. Studies on Limit Dextrinase in Barley. I. Purification of Malt Limit Dextrinase and Production of Specific Monospecific Antibodies. Journal of Cereal Science 16: 107-116.

75. Skendi A, CG Biliaderis, M Papageorgiou and MS Izydorczyk. 2010. Effects of two barley $\beta$-glucan isolates on wheat flour dough and bread properties. Food Chemistry 119: 1159-1167.

76. Sosulski F, K Krygier and L Hogge. 1982. Free, esterified, and insoluble-bound phenolic acids. 3.Composition of phenolic acids in cereal and potato flours. Journal of Agricultural and Food Chemistry 30: 337-340.

77. Stahl Y, RD Alexandra, S Coates, JH Bryce, HR Jenkinson and PC Morris. 2007. The Barley Limit Dextrinase Inhibitor: Gene Expression, Protein Location and Interaction With 14-3-3 Protein. Plant Science 172: 452-461.

78. Swanston JS and JL Molina-Cano. 2001. $\beta$-amylase activity and thermostability in two mutants derived from the malting barley cv. Triumph. Journal of Cereal Science 33: 155-161.

79. Takahashi R. 1955. The origin and evolution of cultivated barley. Advances in Genetics 7: 227-266.

80. Taketa S, S Amano, Y Tsujino, T Sato, D Saisho, K Kakeda, M Nomura, T Suzuki, T Matsumoto, K Sata, H Kanamori, S Kawasaki and K Takeda. 2008. Barley grain with adhering hulls is controlled by an ERF family transcription factor gene regulating a lipid biosynthesis pathway. Proceedings of Nationalr Academy of Sciences 105: 4062-4067.

81. Tang Y, X Zeng, Y Wang, L Bai, Q Xu, Z Wei, H Yuan and T Nyima. 2017. Transcriptomics analysis of hulless barley during grain development with a focus on starch biosynthesis. Functional Integrative Genomics 17: 107-117.

82. Topping DL and PM Clifton. 2001. Short-chain fatty acids and human colonic function: Roles of resistant starch and non-starch polysaccharides. Physiological Review 81: 1031- 1064.

83. Vasan A, M Mani and P Boora. 2014. Barley foods and health: Opportunities ahead. 2014. International Conference on Intelligent Agriculture. IPCBEE 63: 2014.

84. Virkki L, L Johansson, M Ylinen, S Manau and P Ekholm. 2004. Structural characterization of water insoluble non-starch polysaccharides of oats and barley. Carbohydrate Polymers 59: 357-366.

85. Xiong Y, N Miyamoto, K Shibata, MA Valasek, T Motoike, RM Kedzierski and M Yanagisawa. 2004. Short-chain fatty acids stimulate leptin production in adipocytes through the $\mathrm{G}$ protein-coupled receptor GPR41. Proceedings of National Academy of Sciences USA 101: 1045-1050.

86. Yu L, S Haley, J Perret, M Harris, J Wilson and M Qian. 2002. Free radical scavenging properties of wheat extracts. Journal of Agricultural and Food Chemistry 50: 1619-1624.

87. Zhao H, W Fan, J Dong, J Lu, J Chen, L Shan, Y Lin and W Kong. 2008. Evaluation of antioxidant activities and total phenolic contents of typical malting barley varieties. Food Chemistry 107: 296304 .

88. Zheng GH, BG Rossnagel, RT Tyler and RS Bhatty. 2000. Distribution of $\beta$-glucan in the grain of hull-less barley. Cereal Chemistry 77: 140-144.

89. Zielinski $\mathrm{H}$ and $\mathrm{H}$ Kozlowska. 2000. Antioxidant activity and total phenolics in selected cereal grain and their different morphological fractions. Journal of Agricultural and Food Chemistry 48: 2008-2016. 